\title{
RAP: A Reading Comprehension Strategy for Students with Learning Disabilities and Concomitant Speech-Language Impairments or ADHD
}

\author{
Suzanne E. Kemp (Corresponding Author) \\ University of Nebraska-Lincoln \\ 353 Barkley Memorial Center \\ University of Nebraksa Lincoln 68583-0738, USA \\ E-mail: skemp2@unl.edu
}

Received: March 9, 2017

doi:10.5296/jet.v4i2.11614
Accepted: March 17, 2017

Published: July 28, 2017

URL: http://dx.doi.org/10.5296/jet.v4i2.11614

\begin{abstract}
Students with learning and language disabilities and those with attention deficit hyperactivity disorder (ADHD) frequently struggle with reading comprehension. The purpose of this study was to investigate the efficacy of a paraphrasing cognitive strategy that consists of read, ask, put (RAP) on reading comprehension. In addition, the maintenance effects two months after treatment for three students with learning disabilities either concomitant speech-language impairmenst or ADHD was also studied. Read, ask, put was taught using the Strategic Intervention Model (SIM). A multiple baseline design across participants was used with three fourth grade students with learning disabilities. Results indicated the use of RAP had a positive effect on reading comprehension with the most substantial gains for inferential comprehension questions. Two months after intervention, all three students either maintained gains in reading comprehension from baseline or continued to improve their reading comprehension during maintenance.
\end{abstract}

Keywords: Reading comprehension, attention deficit disorder, hyperactivity disorder, learning disabilities

\section{RAP: A Reading Comprehension Strategy for Students with Learning Disabilities and Concomitant Speech-Language Impairment or ADHD}

Students with learning disabilities (LD) have experienced academic problems in math, writing, expressive and receptive language, and reading (Lerner \& Johns, 2015). They also have difficulties with information processing including short-term memory, working memory, problem-solving skills, strategy selection, and monitoring performance (Martin, Martin, \& Carvalho, 2008). These deficits most commonly impact the area of reading (Hallahan, Lloyd, Kauffman, Weiss, \& Martinez, 2005). Typical difficulties include phonological processing, 
decoding, fluency, and comprehension (Eisenmajer, Ross, \& Pratt, 2005; Hallahan et al., 2005). In addition to these problems, students with LD do not develop their own reading strategies, especially in the area of reading comprehension, and do not know how to adjust their reading to aid comprehension (Antoniou \& Souvignier, 2007)

Cognitive strategy instruction has been effective for improving both elementary and secondary students with LD reading comprehension (Faggella-Luby \& Deshler, 2008; Swanson \& Orosco, 2013). In this approach, students are taught to monitor their own reading comprehension through the use of such techniques as questioning, summarizing, mental imagery, story grammar, and paraphrasing (Pressley \& Woloshyn, 1995). It has produced improvements in reading comprehension for students with LD ranging from fourth grade to seventh grade implemented in both special and general education settings (Baker, Gersten, \& Scanlon, 2002; Peat, Wilgosh, \& Mulcahy, 1996). Consequently, it is considered one of the most highly effective teaching methods for improving these students' reading comprehension and communication-language skills (Swanson \& Carson, 1996).

One model that is used to delivery cognitive strategy instruction is the Strategic Intervention Model (SIM) developed at the University of Kansas Center for Research on Learning (Schumaker, Deshler, \& Ellis, 1986). The SIM contains eight steps for teaching cognitive strategies: (a) Pretest and make commitments, (b) strategy description, (c) modeling the strategy, (d) verbal practice, (e) controlled practice and feedback, (f) advanced practice and feedback, (g) posttest and commitment to generalize, and (h) generalization (Ellis, Deshler, Lenz, Schumaker, \& Clark, 1991).

One specific cognitive strategy that has been taught to students with LD using the SIM is a paraphrasing strategy consisting of three steps: (a) Read a paragraph, (b) Ask myself, "What is the main idea and two details?" and (c) Put the main idea in my own words (Schumaker, Denton, \& Deshler, 1984). The acronym RAP, corresponding to the three components, has been used to describe this strategy. The purpose of RAP is to aid reading comprehension by helping students find the most important information in a given reading selection. Schumaker et al. (1984) found that students improved their reading comprehension $36 \%$ after learning RAP. It also has been effective for increasing reading skills for adolescents in middle school and high school with and without LD (Ellis \& Graves, 1990; Hagaman \& Reid, 2008; Katims \& Harris, 1997; Lauterbach \& Bender, 1995; Lee \& Von Colln, 2003). Hagaman, Casey, and Reid (2012) found the RAP strategy increased reading comprehension of third grade students who were fluent readers but experienced difficulty with comprehension. However, no study to date has investigated the efficacy of RAP for improving the reading skills of elementary-level students with learning disabilities and either concomitant speech-language impairments or attention-deficit hyperactivity disorder (ADHD).

\section{Methods}

\subsection{Participants}

Three fourth grade students who were verified as learning disabled either through 
standardized tests of achievement and intelligence (i.e., achievement scores that were at least 20 points below her IQ scores) or through a Response to Intervention (RtI) process (i.e., performance below the $12^{\text {th }}$ percentile on district norms after 16 weeks of intense reading intervention). In addition to verification as learning disabled, they also had to meet the following criteria: performance below the $60^{\text {th }}$ percentile on the reading comprehension section of the Iowa Test of Basic Skills which was completed at the end of third grade, teacher nomination based on past anecdotal data regarding reading comprehension performance, and performance on Leveled Reading Passages developed by Houghton Mifflin that was at least one semester behind grade level. Assessment based on the leveled reading passages measured reading accuracy, fluency, and comprehension. These passages are coded with letters that correspond to certain grade levels. None of the students received free or reduced lunch.

2.11 Molly. Molly was a 9 year, 9 month old Caucasian identified as LD. Her reading comprehension score on the Iowa Test of Basic Skills (ITBS) was in the $57^{\text {th }}$ percentile, but her classroom teachers, previous special education teacher, and speech-language pathologist all described Molly's reading comprehension performance as inconsistent. Past examples of her inconsistent reading comprehension performance included (a) receiving an $80 \%$ or above on a reading comprehension worksheet or test on one occasion and receiving less than $50 \%$ on another similar worksheet or test on the same story, (b) retelling one story in its entirety, but not able to retell another similar story even with the same amount of background knowledge on both stories, and (c) answering oral comprehension questions with $80 \%$ accuracy about one story, but then answering oral comprehension questions about another story with less than 50\% accuracy. Molly also qualified as a student with a speech-language impairment and experienced difficulties with both receptive and expressive language.

2.12 Edward. Edward was a 9 year, 11 month old Caucasian. Besides having a learning disability, he also qualified as a student with a speech-language impairment. Edward struggled in the area of expressive language. On the ITBS, his vocabulary score was in the $30^{\text {th }}$ percentile, reading comprehension was in the $29^{\text {th }}$ percentile, and total reading score was in the $30^{\text {th }}$ percentile. When given third grade reading passages by the speech pathologist at the beginning of this year, Edward was able to answer inferential comprehension questions $14 \%$ of the time. At the start of fourth grade, Edward passed a Leveled Reading Passage that was the equivalent of beginning third grade reading material.

2.13 Shane. Shane was a 9 year, 3 month old African-American with a learning disability. He was also receiving services under the Other Health Impairment (OHI) category due to a pediatrician's diagnosis of Attention Deficit Hyperactivity Disorder (ADHD). Shane's classroom behaviors were interfering with his academic growth and performance. He walked around the classroom, talked out of turn during instruction, touched objects around him (e.g., his pencil, paper, and clothes), and talked about other topics while completing academic tasks. On the Iowa Test of Basic Skills, his vocabulary score was in the $41^{\text {st }}$ percentile, reading comprehension was in the $34^{\text {th }}$ percentile, and total reading score was in the $38^{\text {th }}$ percentile. At the beginning of fourth grade, Shane passed a Leveled Reading Passage, which was the equivalent to beginning third grade reading material. 


\subsection{Setting}

This study was conducted at an elementary school in a mid-west school district. The population of the school included 491 students with $6 \%$ minority, $10 \%$ gifted, $15 \%$ placed in special education, and 20\% eligible for free/reduced lunch. All phases of the study took place in a resource room during reading group. The resource room was 22 feet by 35 feet and had one kidney-shaped table on the north and south side of the room with two trapezoid tables located in the center of the room. RAP instruction took place at one kidney-shaped table while the other students were at the other kidney-shaped table. The distance between the two kidney-shaped tables was 20 feet.

\subsection{Dependent Measures}

Two dependent measures were collected throughout this study: (a) percentage of correct literal questions and (b) percentage of correct inferential questions. Each probe contained five literal questions and five inferential questions. To determine the percentage correct for each type of question, the number of correct responses was divided by the total number of questions. Probes were developed from the Timed Readings Plus Book One that contained fourth grade reading material (Spargo, 2001). Timed Readings were selected because they had been used in a previous study investigating the RAP strategy (Katims \& Harris, 1997). In addition, Timed Readings contained expository reading passages and questions that were similar to reading activities and tests students complete during typical reading lessons. Many of the passages children read at school contain expository text, however, learning how to comprehend expository text has been highly ignored in elementary schools' curricula (Williams, Hall, \& Lauer, 2004). Timed Readings Plus Book One provided an answer key for each probe of ten multiple-choice questions. After the experimenter scored each probe, a special education teacher also scored each probe. Interrater reliability was $100 \%$.

\subsection{Experimental Design}

A multiple baseline design was used across participants. This design required some participants to remain in baseline while others were being taught RAP. Repeated measurements were initially conducted across comprehension assessments to obtain baselines on all participants. Repeated measurements across participants continued while treatment was introduced sequentially across participants, but never concurrently. When one child was receiving treatment, the other participants were either under baseline or maintenance conditions. Once treatment was terminated for a certain participant, subsequent maintenance checks through use of the probes were collected for two months.

\subsection{RAP Strategy}

RAP was taught using the SIM during one-on-one instruction using the following steps:

1. Pretest and make commitments. Participants were pre-tested during baseline phases. They were asked to read a passage and then answer ten comprehension questions pertaining to the passage. After baseline data was obtained, participants were asked if they were ready to commit to learning RAP as a "trick" to improve their reading comprehension. 
2. Describe the strategy. The teacher described what RAP is used for, where it can be used, when it can be used, and why it should be used. Participants were then told what each step of the RAP stood for:

R: Read a Paragraph.

A: Ask yourself what is the main idea and two details.

P: Put the main idea into your own words.

3. Model the strategy. The teacher used a think-aloud to verbally model the steps of the strategy. During this think-aloud, the teacher modeled meta-cognitive statements including "What do I do next?" "What is the next step?" "What does it mean to put something into my own words?"

4. Verbal practice. Participants rehearsed and memorized the strategy to $100 \%$ accuracy as determined when they could verbally state all three steps of RAP without teacher prompts or using a cue card. All three students were able to memorize the steps of RAP after one session. The steps of RAP were memorized with verbal rehearsal, written rehearsal, and physical activity including throwing a ball back and forth while practicing saying each step of the strategy aloud. Also, participants rehearsed where to first look for a main idea of a paragraph, how to find two details, and putting main ideas into their own words.

5. Controlled practice and feedback. Participants were instructed to read the grade-level passages aloud and use RAP for every paragraph. The teacher and participants practiced RAP together and assisted each other while using the strategy. Participants were also allowed to look at a prompt card that contained the RAP steps. When every paragraph of the passage had been read and RAP had been used, participants then answered 10 multiple-choice questions about the passage and received corrective feedback such as reminding them to think back about the main ideas and details while trying to find the correct answer.

6. Advanced practice and feedback. Participants continued to practice RAP until they were able to use it independently_meaning that all steps were applied to a paragraph. Teacher feedback was only given when needed. For example, when a participant was able to use the first two steps of RAP accurately and independently, but was not able to put the main idea into their own words, the teacher gave feedback regarding only the latter. The teacher would say, "We are on the last step which is putting the main idea into your own words. Tell me how you would put the main idea into your own words without copying the exact words from the book. Then, I can help you." The prompt card containing the steps of RAP was not used during this time.

7. Posttest and commitment to generalize. Participants were asked to use this strategy in the general education classroom. The teacher specifically told them, "I want you to use RAP in the classroom whenever you need to remember what you read. You can use RAP during reading class, guided reading groups, health, social studies, and science. During the week, I am going to ask you if you used RAP and for what subject." 
8. Generalization. Participants reported whether they used RAP in the general education classroom and for which subjects. The general education teachers were also informed about the new strategy so they could encourage the use of RAP in their classroom while students were reading.

\subsection{Procedures}

2.6.1 Baseline. The order of participants in baseline was determined by teacher knowledge of the students, including how quickly each could independently use the strategy based on past academic performance. It was determined that Molly and Shane would take the least amount of time to learn and apply RAP, so Molly received instruction first and Shane received instruction last. Edward received instruction second because it appeared he would take the longest amount of time to learn and apply RAP. Baseline consisted of at least five data points in an attempt to achieve a stable trend. Each participant was probed with comprehension passages five times or more until a stable baseline was obtained. Stability was determined when a reasonable level and trend were noted which justifies a phase change (Barlow, Nock, \& Hersen, 2008). After the baseline phase, each student participated in a treatment phase. Phase changes between baseline and treatment were staggered between students. All students began the baseline phase at the same time.

During baseline, each student read five reading passages taken from Timed Readings Plus Book One (Spargo, 2001). Participants were asked to read each passage aloud. They were told they could ask the teacher for assistance on pronunciation of any unknown words, but there was not any additional assistance given including prompts or praise. After reading the passage, participants turned over the paper to the questions on the back. The question and answer choices were read aloud while the students marked their answers. This process took between seven to 15 minutes.

2.6.2 RAP Treatment. Molly received treatment immediately after a stabilized baseline of five data points was obtained. Edward continued baseline until a reasonably clear intervention effect was noted in Molly. Similarly, Shane continued baseline until intervention effects were shown for both Molly and Edward. Each participant received instruction for using RAP. Treatment took eight, nine, and seven sessions for Molly, Edward, and Shane, respectively. Treatment was terminated for a participant once he or she could use RAP without any teacher prompts and completed all four probes.

After steps one through five of the SIM were complete, the first probe was given which was an unknown passage with 10 multiple-choice questions from Timed Readings Plus Book One (Spargo, 2001). After the first probe was given, steps six and seven of SIM were rehearsed. After steps six and seven were rehearsed, RAP practice took place until the student could independently use RAP without any teacher prompts. Once a student could use RAP without any teacher prompts, the student was given three unknown reading passages with 10 multiple-choice questions from Timed Readings. The remaining three probes were given on three separate days. The probes were given under the same conditions as the baseline probes with the same directions. RAP data were gathered in the resource room 12 times. Data collection took between seven to 15 minutes depending on each student's reading rate of 
the passage and time used to answer the 10 multiple choice questions.

2.6.3 Maintenance. Maintenance probes were administered once every two weeks for two months after treatment. Maintenance probes were administered in the same way that baseline probes and treatment probes were administered.

\section{Results}

The mean scores, ranges, and percentage of non-overlapping data are presented in Table 1. The percentage of non-overlapping data (PND) points examined how data from one phase changed from the data collected in the following phase (Scruggs, Mastropieri, \& Casto, 1987). Interpretation of this approach is based on percentages obtained $(<90 \%=$ highly effective, $70 \%$ - 90\% - moderately effective, $50 \%-70 \%=$ minimally effective, $>50 \%$ ). Figures 1 and 2 present the multiple baseline design for literal and inferential questions, respectively.

Table 1. Mean Scores, Range, and Percentage of Non-Overlapping Data

\begin{tabular}{|c|c|c|c|c|c|c|c|c|}
\hline \multirow[t]{2}{*}{ Participant } & \multicolumn{2}{|c|}{ Baseline } & \multicolumn{3}{|c|}{ RAP Intervention } & \multicolumn{3}{|c|}{ Maintenance } \\
\hline & Mean & Range & Mean & Range & $\%$ of Non-Overlap & Mean & Range & of Non-Overlap \\
\hline \multicolumn{9}{|l|}{ Molly } \\
\hline $\mathrm{BR}$ & $64 \%$ & $60-80 \%$ & $65 \%$ & $40-80 \%$ & $75 \%$ & $83 \%$ & $80-100 \%$ & $85.7 \%$ \\
\hline UI & $52 \%$ & $40-80 \%$ & $70 \%$ & $20-100 \%$ & $25 \%$ & $63 \%$ & $60-80 \%$ & $100 \%$ \\
\hline \multicolumn{9}{|l|}{ Edward } \\
\hline $\mathrm{BR}$ & $63 \%$ & $20-80 \%$ & $85 \%$ & $80-100 \%$ & $100 \%$ & $88 \%$ & $80-100 \%$ & $100 \%$ \\
\hline UI & $40 \%$ & $20-80 \%$ & $70 \%$ & $60-80 \%$ & $100 \%$ & $72 \%$ & $60-100 \%$ & $80 \%$ \\
\hline \multicolumn{9}{|l|}{ Shane } \\
\hline $\mathrm{BR}$ & $83 \%$ & $60-100 \%$ & $90 \%$ & $80-100 \%$ & $100 \%$ & $80 \%$ & $80 \%$ & $100 \%$ \\
\hline UI & $50 \%$ & $0-60 \%$ & $75 \%$ & $60-100 \%$ & $100 \%$ & $75 \%$ & $60-100 \%$ & $100 \%$ \\
\hline
\end{tabular}

Note. $\mathrm{BR}=$ Literal; $\mathrm{UI}=$ Inferential

\subsection{Molly}

During baseline, Molly's mean score for the literal questions was $64 \%$ and increased to $65 \%$ after intervention. Her mean score for inferential questions was 52\% during baseline and improved to $70 \%$ after intervention. After two months of maintenance checks, her mean score for literal questions increased to $83 \%$, and her mean score for inferential questions decreased to $63 \%$, but was still higher than her baseline level. Visual inspection of Figures 1 and 2 indicated that Molly's baseline was stable prior to treatment. During treatment, Molly displayed a stable trend in Figure 1 for literal questions and an ascending trend in Figure 2 for inferential questions. 


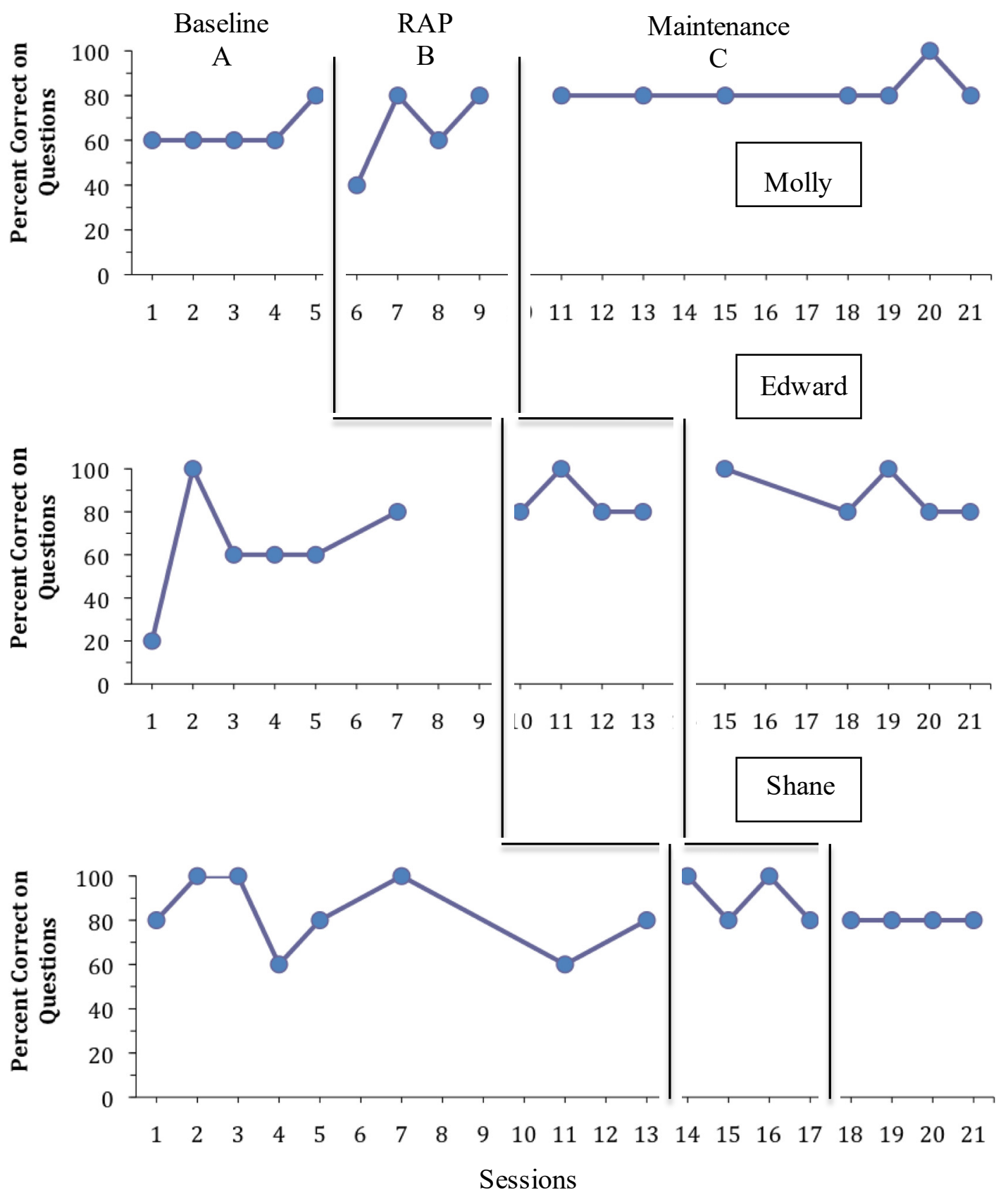

Figure 1. Percentage scores for literal questions 


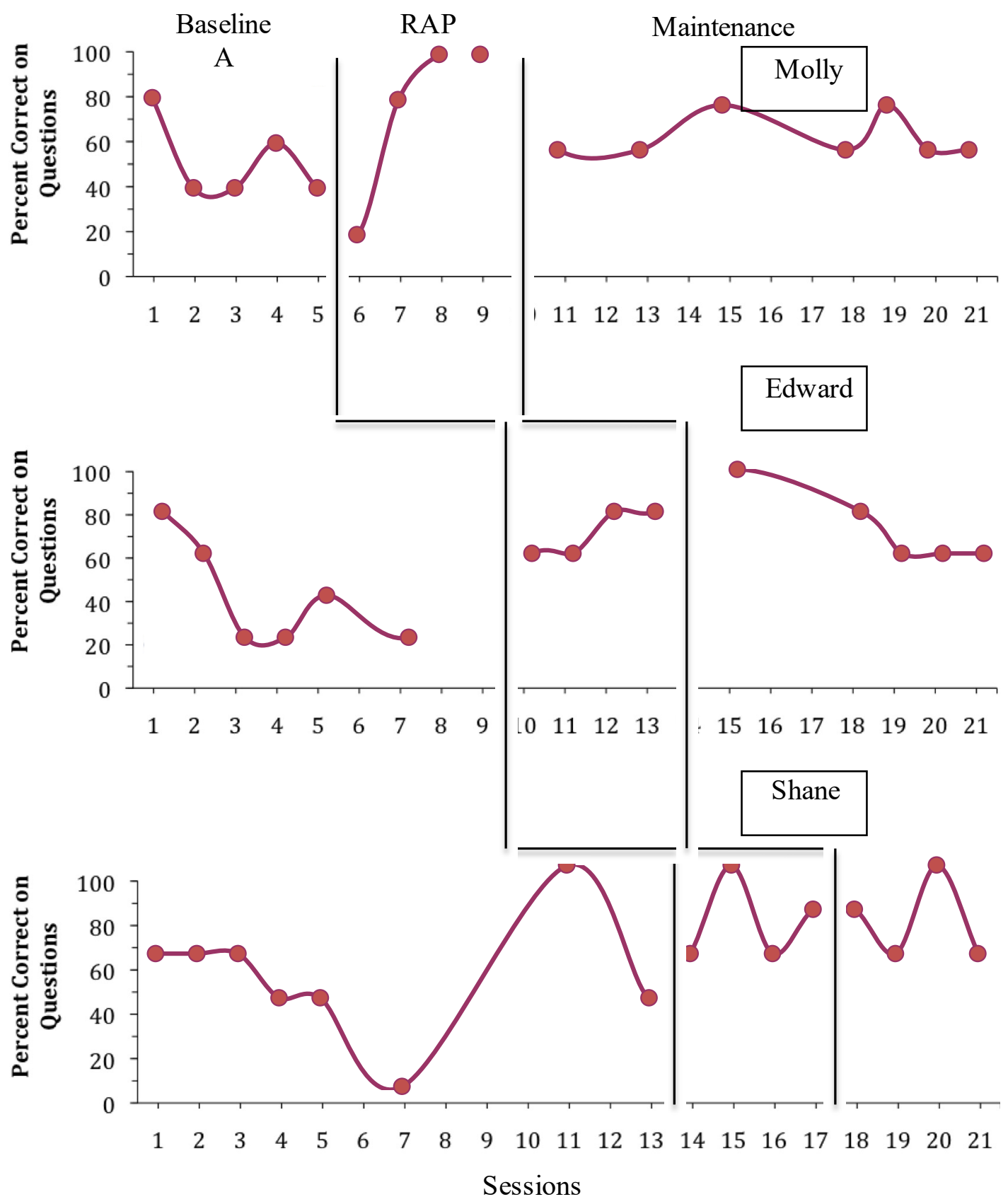

Figure 2. Percentage scores for inferential questions

\subsection{Edward}

During baseline, Edward's mean score for the literal questions was $63 \%$ and increased to $85 \%$ after intervention. His mean score for inferential questions during baseline was $40 \%$ and his mean score increased to $70 \%$ after intervention. After two months of maintenance checks, his mean score for literal questions increased to $88 \%$ and his mean score for inferential questions increased to $72 \%$. Visual inspection of Figures 1 and 2 indicated Edward's 
baseline was stable prior to treatment. During treatment, Edward displayed a stable trend in Figure 1 for literal questions and an ascending trend in Figure 2 for inferential questions.

\subsection{Shane}

During baseline, Shane's mean score for literal questions was $83 \%$ and increased to $90 \%$ after intervention. His mean score for inferential questions was $50 \%$ during baseline and $75 \%$ after intervention. After two months of maintenance checks, his mean score for literal questions decreased to $80 \%$ and his mean score for inferential questions remained at $75 \%$. Visual inspection of Figures 1 and 2 indicated Shane's baseline was variable throughout. During treatment, Shane displayed a stable trend in Figure 1 for literal questions and an unstable trend in Figure 2 for inferential questions. However, the range of his scores for inferential questions was higher than his range during baseline as seen in Table 1.

\section{Discussion}

The purpose of this study was to determine if RAP improved the comprehension scores of elementary students with LD and whether results were maintained two months after it was discontinued. Literal questions pertained to facts directly stated in reading passages. Inferential questions required using prior knowledge to make deductions about the questions. Three results were obtained from the present study. First, RAP had little effect on literal comprehension. Second, RAP substantially improved participants' inferential reading comprehension. Third, increases in reading comprehension were maintained, and in some cases even improved, two months after RAP was discontinued.

\subsection{Cognitive Strategies and Literal Comprehension}

The RAP intervention did not result in substantial improvements for literal comprehension questions, although some small gains were obtained. Literal comprehension is based on information that is directly stated in a reading passage. Although literal comprehension requires problem-solving skills, it does not require as many higher-level thinking skills as inferential comprehension. In order to answer inferential questions, readers must fill in missing information with prior knowledge and make deductions about the questions (Davey \& Macready, 1990). Therefore, it makes sense that a cognitive strategy such as RAP would produce more substantial gains for inferential comprehension instead of literal comprehension. Previous researchers demonstrated improvements in answering multiple-choice or open-ended comprehension questions similar to the present study with the RAP strategy (Ellis \& Graves, 1990; Hagaman et al., 2012; Hagaman \& Reid, 2008; Katims \& Harris, 1997; Lauterbach \& Bender, 1995; Lee \& Von Colln, 2003). Of those studies, only the Hagaman and Reid and Hagaman and colleagues' studies addressed positive treatment effects for both literal and inferential questions. Results of the present study regarding literal comprehension corroborate those two. The present study also extended the literature by using RAP with students with learning disabilities and addressed maintenance of treatment gains. 


\subsection{Inferential Comprehension Improvement}

The RAP instruction resulted in substantial improvements in participants' inferential reading comprehension. Unlike previous researchers who found improvements when students answered multiple-choice or open-ended comprehension questions (Ellis \& Graves, 1990; Katims \& Harris, 1997; Lauterbach \& Bender, 1995; Lee \& Von Colln, 2003), the present study also produced positive results for inferential comprehension such as those obtained by Hagaman \& Reid (2008) and Hagaman et al. (2012) but extended to students with learning disabilities.

Results of the present study may also have implications for improving standardized reading test scores for elementary-age students with learning disabilities. For example, Brown, Pressley, Van Meter and Schuder (1996) found improvements in standardized reading test scores after struggling readers received cognitive strategy. Based on the results of the present research with fourth graders, the RAP, may also improve standardized reading comprehension scores of students with learning disabilities who struggle in this area.

\subsection{RAP, Language Problems, and ADHD}

Students with language impairments may also struggle with reading comprehension due to deficiencies in integrating information and making inferences, understanding text structure, and monitoring comprehension (Kelso, Fletcher, \& Lee, 2007). Two of the participants in the present study, Molly and Edward, were identified as having a language disorder in addition to a learning disability. They both demonstrated substantial improvements in answering inferential questions after receiving RAP. Using RAP aided monitoring comprehension because part of the strategy included stopping after reading a paragraph and having participants state the main ideas and two details in their own words. Takala (2006) previously found that fourth and sixth grade students with language impairments demonstrated improved reading comprehension from post-tests after receiving cognitive strategy instruction.

Struggles with reading comprehension have been documented in students with reading disabilities and ADHD (Ghelani, Sidhu, Jain, \& Tannock, 2004). Reading comprehension performance of students with ADHD has often decreased as reading passage length increased (Cherkes-Julkowski, Stolzenberg, Hatzes, \& Madaus, 1995). Brock and Knapp (1996) found that students with ADHD had difficulties stating main ideas from reading passages. The RAP strategy provided a structure with steps that addressed both issues for Shane who was diagnosed with ADHD in additional to having a learning disability. When using RAP, a student needs to stop after each paragraph to state the main ideas and two details in their own words. This step breaks up a long reading passage into more manageable sections to support comprehension.

\subsection{Maintenance}

The RAP intervention resulted in maintenance of treatment effects for all three participants. Two participants experienced continued improvement during maintenance for literal comprehension. The reasons for why literal comprehension continued to improve during 
maintenance are unknown and speculative. One possible reason why literal comprehension continued to improve during maintenance was because participants reported using RAP in their general education classrooms that, consequently, may have lead to additional practice. Past researchers using RAP only conducted maintenance probes for up to two weeks (Ellis \& Graves, 1990; Hagaman \& Reid, 2008; Lauterbach \& Bender, 1995). Therefore, present study adds to the literature on RAP because maintenance probes were conducted for two months after intervention and positive gains still occurred.

\section{Limitations and Future Research}

There are some limitations in the present study. First, there was the lack of empirical research for the assessment material, Timed Readings Plus Book One. A search on Academic Search Premier and PsycINFO did not provide any information about Timed Readings Plus Book One. However, Timed Readings was used in a RAP study conducted by Katims and Harris (1997). Second, RAP was taught and assessed by one of the researchers. Teacher implementation has been less successful in early childhood settings than researcher implementation (Byrne \& Fielding-Barnsley, 1995). Although this study was conducted in an elementary school and not in an early childhood setting, the same issue may have existed. Third, the multiple-choice test items and possible answers were read aloud to participants. This was done because the purpose of the study was to measure comprehension, not focus on decoding - a practice also used by Hagaman and Reid (2008).

Future research should determine the efficacy of RAP when taught and assessed by different people with varying degrees of experience. The simplicity and structure of RAP may make it possible for paraeducators to work one-on-one with struggling readers and, thereby freeing up teachers. Another area for further investigation would be determining if there were differences in comprehension scores when participants read the test items and answers as compared to when test items and answers were read aloud. Future research should also focus on assessing generalization of RAP. In order for students with LD to be successful in general education classrooms, it is important that they use learned strategies across a variety of settings and contents. Finally, future research should replicate RAP studies, such as the present study, with larger numbers of participants with LD and/or varying disabilities to establish external validity.

\section{References}

Antoniou, F., \& Souvignier, E. (2007). Strategy instruction in reading comprehension: An intervention study for students with learning disabilities. Learning Disabilities -- $A$ Contemporary Journal, 5(1), 41-57.

Baker, S., Gersten, R., \& Scanlon, D. (2002). Procedural facilitators and cognitive strategies: Tools for unraveling the mysteries of comprehension and the writing process, and for providing meaningful access to the general curriculum. Learning Disabilities Research \& Practice, 17(1), 65-77.

Barlow, D. H., Nock, M. K., \& Hersen, M. (2008). Single case experimental designs: Strategies for studying behavior change (3rd ed.). New York, NY: Pearson. 
Brock, S., \& Knapp, P. (1996). Reading comprehension abilities of children with attention deficit/hyperactivity disorder. Journal of Attention Disorders, 1, 173-186.

Brown, R., Pressley, M., Van Meter, P., \& Schuder, T. (1996). A quasi-experimental validation of transactional strategies instruction with low-achieving second grade readers. Journal of Educational Psychology, 88(1), 18-37.

Byrne, B., \& Fielding-Barnsley, R. (1995). Evaluation of the program to teach phonemic awareness to young children: A 2- and 3-year follow-up and a new preschool trial. Journal of Educational Psychology, 87(3), 488-503.

Cherkes-Julkowski, M., Stolzenberg, J., Hatzes, N., \& Madaus, J. (1995). Methodological issues in assessing the relationship among ADD, medication effects and reading performance. Learning Disabilities: A Multidisciplinary Journal, 6, 21-30.

Davey, B., \& Macready, G. (1990). Applications of latent class modeling to investigate the structure underlying reading comprehension items. Applied Measurement in Education, 3(3), 209.

Eisenmajer, N., Ross, N., \& Pratt, C. (2005). Specificity and characteristics of learning disabilities. Journal of Child Psychology \& Psychiatry, 46(10), 1108-1115.

Ellis, E. S., Deshler, D. D., Lenz, B. K., Schumaker, J. B., \& Clark, F. L. (1991). An instructional model for teaching learning strategies. Focus On Exceptional Children, 22(9), 1-16.

Ellis, E. S., \& Graves, A. W. (1990). Teaching rural students with learning disabilities: A paraphrasing strategy to increase comprehension of main ideas. Rural Special Education Quarterly, 10, 2-10.Faggella-Luby, M., \& Deshler, D. (2008). Reading comprehension in adolescents with LD: What we know; what we need to learn. Learning Disabilities Research \& Practice, 23(2), 70-78.

Ghelani, K., Sidhu, R., Jain, U., \& Tannock, R. (2004). Reading comprehension and reading related abilities in adolescents with reading disabilities and attention-deficit/hyperactivity disorder. Dyslexia, 10(4), 364-384.

Hagaman, J. L., Casey, K. J., \& Reid, R. (2012). The effects of the paraphrasing strategy on the reading comprehension of young students. Remedial and Special Education, 33, 110-123.

Hagaman, J. L., \& Reid, R. (2008). The effects of the paraphrasing strategy on the reading comprehension of middle school students at risk for failure in reading. Remedial \& Special Education, 29(4), 222-234.

Hallahan, D., Lloyd, J., Kauffman, J., Weiss, M., \& Martinez, E. (2005). Learning disabilities: Foundations, characteristics, and effective teaching (3rd ed.). Boston, MA: Pearson Education.

Katims, D. S., \& Harris, S. (1997). Improving the reading comprehension of middle school 
students in inclusive classrooms. Journal of Adolescent and Adult Literacy, 41, 116-123.

Kelso, K., Fletcher, J., \& Lee, P. (2007). Reading comprehension in children with specific language impairment: an examination of two subgroups. International Journal of Language \& Communication Disorders, 42(1), 39-57.

Lauterbach, S. L., \& Bender, W. M. (1995). Cognitive strategy instruction for reading comprehension: A success for high school freshmen. High School Journal, 79, 58-64.

Lee, S. W., \& Von Colln, T. (2003). The effect of instruction in the paraphrasing strategy on reading fluency and comprehension. Retrieved from Educational Resources Information Center.

Lerner, J. W., \& Johns, B. (2015). Learning disabilities and related disabilities: Strategies for success. Boston, MA: Cengage.

Martin, D., Martin, M., \& Carvalho, K. (2008). Reading and learning-disabled children: Understanding the problem. Clearing House, 81(3), 113-118.

Peat, D., Wilgosh, L., \& Mulcahy, R. (1996). Efficacy of cognitive strategy-based instruction for elementary students with learning disabilities: A retrospective study. Canadian Journal of School Psychology, 12, 135-142.

Pressley, M., \& Woloshyn, V. (1995). Cognitive strategy instruction that really improves children's academic performance (2nd ed.). Cambridge, MA: Brookline Books.

Schumaker, J. B., Denton, P. H., \& Deshler, D. D. (1984). The paraphrasing strategy: Instructor's manual. Lawrence: University of Kansas Institute for Research on Learning.

Schumaker, J. B., Deshler, D. D., \& Ellis, E. S. (1986). Intervention issues related to the education of LD adolescents. In J. K. Torgeson \& B. Y. L Wong (Eds.), Learning disabilities: Some new perspectives. New York, NY: Academic Press.

Scruggs, T. E., Mastropieri, M. A., \& Casto, G. (1987). The quantitative synthesis of single-subject research: Methodology and validation. Remedial and Special Education, 8, 24-33.

Spargo, E. (2001). Timed readings plus book one. New York, NY: Glencoe McGraw-Hill.

Swanson, H. L., \& Carson, C. (1996). A selective synthesis of intervention research for students with learning disabilities. School Psychology Review, 25(3), 370-392.

Swanson, H. L., \& Orosco, M. (2014). Evidence based reading comprehension programs for students with learning disabilities. In J. Hattie \& E. M. Anderman (Eds.), International guide to student achievement (pp. 448-450). New York, NY: Routledge/Taylor \& Francis Group.

Takala, M. (2006). The effects of reciprocal teaching on reading comprehension in 
mainstream and special (SLI) education. Scandinavian Journal of Educational Research, 50(5), 559-576.

Williams, J., Hall, K., \& Lauer, K. (2004). Teaching expository text structure to young at-risk learners: Building the basics of comprehension instruction. Exceptionality, 12(3), 129-144.

\section{Copyright Disclaimer}

Copyright reserved by the author(s).

This article is an open-access article distributed under the terms and conditions of the Creative Commons Attribution license (http://creativecommons.org/licenses/by/3.0/). 